\title{
Study on Friction and Wear Behavior of SAE 1045 steel, reinforced Nylon 6.6 and NBR Rubber Used in Clutch Disks
}

\author{
Avital Gabriel de Almeida Rosa ${ }^{a, b}$, Jéferson Aparecido Moreto ${ }^{c}$, \\ Marcos Dorigão Manfrinato ${ }^{a}$ Luciana Sgarbi Rossino ${ }^{a, b *}$ \\ ${ }^{a}$ Sorocaba Technological College - FATEC, Av. Engenheiro Carlos Reinaldo Mendes, 2015, \\ Alto da Boa Vista, CEP 18013-280, Sorocaba, SP, Brazil \\ ${ }^{b}$ Federal University of São Carlos - UFSCar, Rodovia João Leme dos Santos, Km 110, \\ Bairro do Itinga, CEP 18052-780, Sorocaba, SP, Brazil \\ 'Federal Institute Goiano - IF Goiano, Rodovia Sul Goiana Km 01, Zona Rural, \\ CEP 75901-970, Rio Verde, GO, Brazil
}

Received: March 19, 2014; Revised: December 17, 2014

\begin{abstract}
The friction and wear properties of AISI 1045 steel, nylon 6.6 composites with different types and percentages of reinforcement and a nitrile rubber, Alpha 66, were submitted to sliding wear tests. The five types of nylon 6.6 composites tested generated matching, low values for the coefficient of friction. This may be due to the greater influence of the nylon 6.6 matrix on the coefficient of friction. However, the wear in nylon composites showed wide variation, determined by the type of reinforcement added to the composite. The other two materials tested, nitrile rubber and 1045 steel, showed behavior different from that of the composites. The NBR (signifying a norm established by the Brazilian Association of Technical Norms) rubber showed a superior coefficient of friction and greater wear. On the other hand, the steel showed a high coefficient of friction and low wear, suggesting that the coefficient of friction has no direct connection to the wear resistance of the materials studied here.
\end{abstract}

Keywords: nylon 6.6, 1045 steel, NBR rubber, coefficient of friction, wear

\section{Introduction}

Component or structure failures may occur due to damage caused by physical deformation, the formation and propagation of cracks, corrosion or wear ${ }^{1}$. However, the degradation of a mechanical component as a result of operating conditions is in most cases concentrated or starts at its surface due to, for example, wear phenomena ${ }^{2}$.

Equipment with moving parts such as ball bearings, pump impellers, spherical valves, gears, pulleys, wear plates, bearings and friction rings that accompany the clutch system, etc., suffer wear. As a result, the repair of equipment and the loss of production cost companies billions ${ }^{3,4}$. It is increasingly important, therefore, to develop materials with improved wear resistance.

It must be considered that wear is not just an intrinsic property of the material, but results from the characteristics of engineering systems (tribosystems). A tribological system includes the surface that suffers wear, the agent of wear and the environment in which the parts involved are acting. Thus, the main factors that contribute to wear are: hardness, toughness, chemical composition, the constitution and microstructure of the materials in contact, pressure, speed, temperature, surface finish, lubrication and corrosion ${ }^{5,6}$.

All materials are prone to these phenomena. However, some materials tolerate or resist wear more and have a low coefficient of friction under certain conditions. Because of

*e-mail: lu-sgarbi@hotmail.com the importance of wear and friction, several studies have been and are being developed to identify the tribological systems that provide a longer service life to parts that undergo wear.

Polymers and reinforced polymers are of interest to some applications involving wear conditions because of their low density, ease of processing and low coefficients of friction and wear ${ }^{7,8}$.

The issue of wear in polymers has gained more attention because of their suitability in the manufacture of machine elements in the food and pharmaceutical industries, as they require no lubrication. However, the group of polymers of tribological interest is restricted. To this group belong PTFE (polytetrafluoroethylene - Teflon $\AA$ ), polyurethanes, UHMWPE (ultra high molecular weight polyethylene), PEEK (polyether-ether-ketone), polyacetals, epoxies, phenolics and polyamides (nylon) ${ }^{9}$.

Nylon 6.6 is a polymeric material that has attracted attention in engineering applications due to its low cost, high mechanical strength and high wear resistance. In some applications, only the nylon is used, but when a higher wear resistance is required, the use of reinforcements in the polymers is recommended to improve their properties.

Nylons are structural plastics and are distinguished from other polymers because they have a good combination of chemical, thermal, mechanical and tribological properties as well as high processability and low $\operatorname{cost}^{10}$. Nylon is a 
polymer of great interest in engineering and that has been well accepted in the aeronautical, automotive, electronics and chemical industries ${ }^{11}$. These materials are used in lowfriction, non-lubricated parts.

One example is the clutch disk system, which requires a material that resists high levels of cycling, has a high resistance to temperature and specific pressure, and whose coefficient of friction is not vulnerable to these temperature variations or specific pressure. The nylon composite meets these requirements well. It is important to know the characteristics of this material when subjected to wear so we can define the project construction parameters.

Owing to their price, the nitrile NBR (signifying a norm established by the Brazilian Association of Technical Norms or ABNT) rubbers, on the other hand, are used in applications where, in addition to desirable mechanical properties or resistance to dynamic fatigue, resistance to swelling in oil or gasoline, heat aging and abrasion is required. They are used in many industries, such as the automobile industry and the mineral oil sector ${ }^{12}$.

The dry clutch, for automotive vehicles with manual transmissions, is located between the engine and transmission and makes use of friction to transmit the rotational movement of the engine to the gearbox. The dry clutch's main function is to engage and disengage the transmission from the engine to allow gear changes and to ensure the transmission of the required torque smoothly and noiselessly. A clutch is basically divided into three parts: the clutch disc, the plateau and the drive system. The clutch disc's primary function is the transmission of torque to the transmission; but, just as important, the clutch disk also has the function of isolating the torsional vibrations generated by the engine. Without proper mitigation, these vibrations cause unwanted noise to the driver. This component is responsible, through friction on the flywheel and brake system's pressure plate, for transmitting the torque required by the vehicle and provided by the internal combustion engine. During the coupling between the engine and transmission, where there is relative velocity or decoupling between the parts, there occurs wear and consequently heating of the material ${ }^{13}$.

It should be noted that, despite the increased number of vehicles with automatic transmissions in the world market, the use of dry disc clutches appears to be stable and without much risk of obsolescence, especially for emerging markets. This further reinforces the need to develop and refine models that represent the current needs of the dry clutch system; that is, considering wear over the service life of each component. This then leads to further discussions on the most detailed modeling of the entire clutch system, from the pedal to the slave cylinder ${ }^{13,14,15}$.

Although wear is rarely catastrophic for a component, it leads to loss of efficiency, vibration and misalignment. In extreme cases, some cracks may lead to fractures, and the fragments formed can often damage the equipment ${ }^{1}$. Thus, the study of the factors which contribute to wear and the precise study of the materials that undergo friction in a particular application are invaluable tools to assess the durability of an assembly safely and reliably, saving time and reducing spending on field tests ${ }^{6}$.
The current study aims to determine the wear resistance and coefficient of friction generated at the contact between 1045 steel and nylon 6.6 composites with different types of reinforcement or Alpha 66 NBR rubber. 1045 steel is used for the manufacture of clutch discs, and it will be assessed if coating one of the components of the assembly with nylon 6.6 and nitrile NBR rubber would increase the service life of the part. In such a case, the nylon composite and rubber would serve as sacrificial materials, thus avoiding the need for replacement of the steel.

\section{Material and Methods}

To determine the wear resistance and coefficient of friction of the tribological systems studied here, we considered AISI 1045 steel in contact with nylon composite materials with different types of reinforcement and nitrile NBR rubber. The metal device, referred to here as antifriction material, has a flat surface and exerts pressure at a given angular velocity directly against another antifriction device. The latter, in turn, with an area of $800 \mathrm{~mm}^{2}$ and a flat surface, is coated with the polymers under study. In the current study, the following polymers are tested:

- nylon 6.6 matrix composite reinforced with $30 \%$ fiberglass and a $15 \%$ TPFE load (N6630\%FG15\% TPFE);

- nylon 6.6 matrix composite reinforced with $10 \%$ carbon fiber and a 20\% TPFE load (N6610\% CF20\%TPFE);

- nylon 6.6 matrix composite reinforced with 20\% aramid fiber (N6620\%AF);

- nylon 6.6 matrix composite reinforced with 25\% fiberglass and 15\% aramid fiber (N6625\%FG15\%AF);

- nylon 6.6 matrix composite reinforced with 35\% glass fiber (N6635\%FG);

- nitrile NBR rubber alpha 66 (Alpha 66);

- uncoated, that is, AISI 1045 carbon steel (Steel).

Table 1 shows the tensile strength values of the materials studied, per the manufacturers' specifications.

Figure 1(a) gives an overview of the friction system used in the present study. The friction ring may be observed between the two flat steel faces (antifriction). The transmission of the motion between the frictional surfaces is performed by the tribological system cube, called the torque transmission hub, which is coupled to the axes of the testing machines, as can be seen in Figure 1(b).

The wear test was performed using the slippage between the tribological systems. The antifriction devices and the

Table 1. Tensile strength of the materials studied.

\begin{tabular}{lc}
\hline \multicolumn{1}{c}{ Material } & Tension Strength [MPa] \\
\hline PA6620\%FA & 85 \\
PA6610\%FC20\%PTFE & 110 \\
PA6630\%FV15\%PTFE & 120 \\
PA6625\%FV15\%FA & 140 \\
PA6635\%FV & 160 \\
NBR & $7-21$ \\
1045 Steel & 570 \\
\hline
\end{tabular}




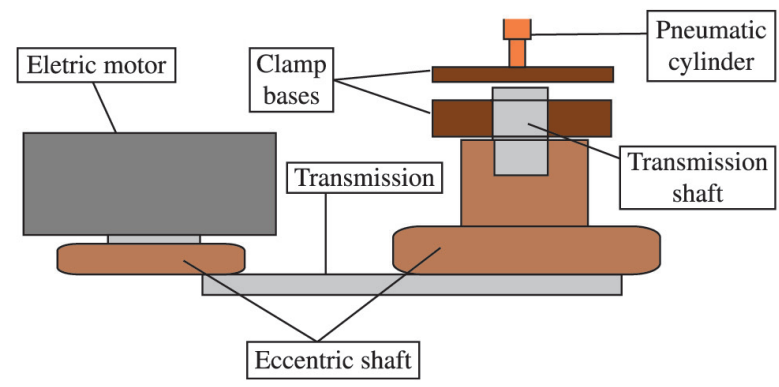

(a)

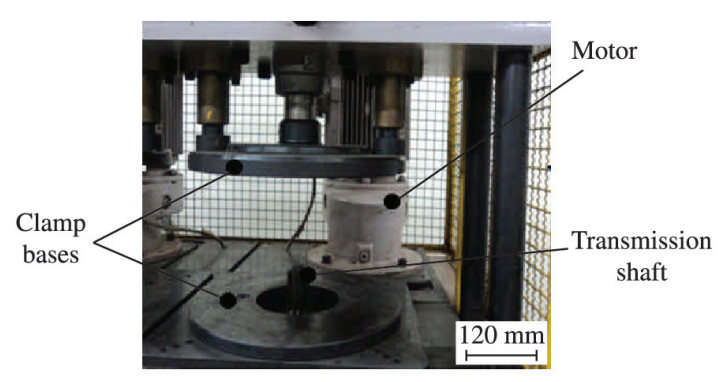

(b)

Figure 1. Diagram of the tribological system used in wear resistance testing and the determination of the coefficients of friction and wear (a) schematic view and (b) system testing.

friction ring were mounted on the drive shaft of the vibration machine. The test parameters are shown in Table 2.

The wear suffered by the materials was determined by measuring the percentage of the volume of the material before and after the test. The higher the wear percentage, the lower its wear resistance under the conditions studied here. The wear evaluation points were chosen in such a way as to scan the entire spectrum of applications to which a frictional assembly may be subjected during actual use. The coefficient of friction was determined using a hysteresis testing machine. The value of the coefficient of friction is defined by Equation (1), where the hysteresis value is given by the testing machine's own software.

$$
\mu=\frac{H_{y}}{\left(2 . \eta \cdot \mu \cdot F_{n} \cdot r_{m}\right)}
$$

where $\mu$ is the material's coefficient of friction, $\mathrm{H}_{\mathrm{y}}$ is the hysteresis of the system, $F_{n}$ is the normal force with which the 1045 steel surface compresses the friction ring against the base of the device, $n$ is the number of surfaces experiencing friction in the assembly and $\mathrm{r}_{\mathrm{m}}$ is the mean radius of the friction ring upon which the plate exerts force.

The fluctuations in the coefficient of friction can be attributed to factors such as wear, oxide breakage, load variation, velocity and with phenomena associated with the removal of wear debris, as well as the vibration created by the moving parts of the equipment or the environment, among others. The average of the coefficient of friction varied for Pantaleón ${ }^{16}$ : in the first $3.000 \mathrm{~s}$, the variation in the mean of the test parameters showed values that decreased. The same behavior was observed for the different test loads; that is, we can predict a convergence of the trends of the measured values and assume they are the moments when the surfaces in contact acquire greatest conformity ${ }^{16}$. Seeing as the variation became constant or zero after $3.000 \mathrm{~s}$, it follows that a stable coefficient of friction process prevails thereafter, and it can be assumed that one wear mechanism is preferred. For the coefficient of friction test, a stabilization period of 20.000 cycles was established for greater test result accuracy.

Temperature varies during the wear test. As discussed by Laranjeira ${ }^{17}$, the effect of the temperature on polymers is very important, as it affects the mechanical properties
Table 2. Test parameters used for wear tests.

\begin{tabular}{lc}
\hline \multicolumn{1}{c}{ Test parameters } & Values \\
\hline Force applied in contact & $600 \mathrm{~N}$ \\
Contact area & $0,0008 \mathrm{~m}^{2}$ \\
Specific pressure & $750 \times 10^{3} \mathrm{Nm}^{2}$ \\
Sliding velocity & $14,05 \mathrm{~m} / \mathrm{min}$ \\
Total cycle & $200000 \mathrm{cycles}$ \\
Sliding distance & $1564 \mathrm{~m}$ \\
\hline
\end{tabular}

and stability of the polymer. Temperature depends on the test conditions and the heat generated by friction at the interface; the dissipation of frictional energy in the contact zone leads to an increase in temperature ${ }^{17}$. To analyze temperature discrepancies, various temperature values were collected every 20.000 cycles - a distance corresponding to 156.4 meters. To this end, we used a Raytek PM plus model PM20 laser temperature measuring instrument. This temperature is influenced by the friction and frequency of contact between the frictional components. The statistical distribution that best models the behavior of the variable was obtained by a piece of software called MinitabTM. Of all the distributions tested, normal distribution was that which best modeled the behavior of the temperature. The calculation of the distribution parameters was done by the maximum likelihood method (MLE), and the choice of distribution was made using the Anderson-Darling test (AD).

\section{Results and Discussion}

\subsection{Determination of wear resistence}

Figure 2 illustrates the percentage of wear suffered by each material. The average temperature for each test is shown in Table 3.

The N6610\%CF20\%PTFE composite showed less wear than the seven other materials tested, as shown in Figure 2. This is because this composite consists of a PTFE load - a material considered a solid lubricant that is very resistant to wear - as well as carbon fiber made of graphite, which is also considered a solid lubricant extremely resistant to wear and an excellent heat dissipater ${ }^{18}$. This heat dissipation characteristic is demonstrated by the lower temperature attained during the wear test, as can be seen in Table 3 . The carbon fibers may be subjected to adverse conditions 
Table 3. Average temperatures reached during the wear test.

\begin{tabular}{lc}
\hline \multicolumn{1}{c}{ Material } & Temperature $\left[{ }^{\circ} \mathbf{C}\right]$ \\
\hline PA6620\%FA & 78.4 \\
PA6620\%PTFE10\%FC & 76.6 \\
PA6630\%FV15\%PTFE & 76.6 \\
PA6615\%FA25\%FV & 79 \\
PA6635\%FV & 77 \\
NBR & 80.4 \\
1045 steel & 114.4 \\
\hline
\end{tabular}

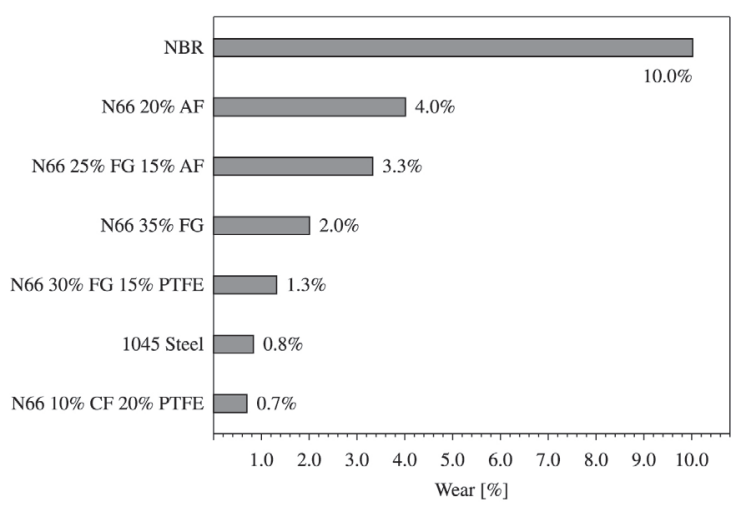

Figure 2. Wear percentage of materials studied.

of temperature and pressure. Even under these conditions, the result was very little wear. It should be noted that, as defined by Laranjeira ${ }^{17}$, the critical working temperature of nylon 6.6 is $85^{\circ} \mathrm{C}^{17}$, which was not reached during testing. As for the 1045 steel, this material showed a minimum wear of $0.8 \%$, which is very close to the wear suffered by N6610\%FG20\%PTFE.

The low wear on the 1045 steel can be explained by its rigidity, which is far superior to the other materials tested here. Another factor that swayed this result was the working temperature. The temperature reached by the steel during the wear test was $114.4{ }^{\circ} \mathrm{C}$, which does not significantly influence its resistance or change its behavior; the melting point of 1045 steel is around $1500{ }^{\circ} \mathrm{C}$, whereas that of the composites is around $250{ }^{\circ} \mathrm{C}$. Ductile materials generally exhibit greater sensitivity to sliding wear than hard materials of a similar kind. However, despite the higher mechanical resistance of the steel than $\mathrm{N} 6610 \% \mathrm{FB} 20 \% \mathrm{PTFE}$, as shown in Table 1. N6610\%FB20\%PTFE is a solid lubricant, which explains its greater resistance to wear.

The N6630\%FG15\%PTFE composite, with test temperatures reaching an average of $76.6{ }^{\circ} \mathrm{C}$, showed $1.3 \%$ wear. This is because this composite had a PTFE load, which is regarded as a solid lubricant that is very resistant to wear, as well as fiberglass - a material with high mechanical strength. The lower wear resistance of N6630\%FG15\%PTFE compared to N6610\%CF20\%PTFE is due to the lesser amount of lubricating material in its composition, which was more efficient in wear resistance for the present study.

The N6635\%FG composite showed 2\% wear. Fiberglass is a material with high mechanical strength, particularly compression, and it is often employed in structural applications. It is important to note that this composite showed lower wear resistance when compared with other composites that possesses lubricant reinforced.

The N6625\%FG15\%AF composite had a $3.3 \%$ wear. It can be concluded that the addition of aramid fiber decreased wear resistance. Comparing the glass fiber composites (N6635\%FG) with aramid fiber composites (N6620\%AF), we see that the high compression factor and temperature favored the fiberglass. Furthermore, fiberglass is heat-stabilized and offers superior strength, rigidity and dimensional stability while maintaining excellent wear resistance ${ }^{17}$.

The N6620\%AF composite was the material with the second worst result ( $4 \%$ wear). The effect that composites with aramid fibers have of decreasing wear resistance was also observed by Zangiacomi ${ }^{19}$ in a study conducted to determine the properties of composites with different reinforcements for use in brake pads ${ }^{19}$. It has been observed that increasing the aramid content in brake pads increased hardness and shear resistance, decreasing density but increasing wear rate from $0.63 \mathrm{~g}$ to approximately $0.85 \mathrm{~g}$. As noted by Bolvari ${ }^{20}$, the wear resistance of the nylon 6.6 matrix composites reinforced with 5 to $15 \%$ aramid exhibit good wear resistance. However, further increasing the amount of aramid causes an increase in wear rate due to the fibrous debris generated, resulting from the poor adhesion of aramid fibers to the matrix ${ }^{20}$. Furthermore, one of the limitations of composites with aramid fiber is their low compressive strength, which may have contributed to a lower wear resistance here ${ }^{21}$. Taking this into account, and considering that the significant difference was the type of reinforcement used in the manufacture of the composite, we see that the reinforcement is fundamental in determining the wear resistance of a polymer matrix. Alpha 66 had the largest amount of wear of all tested materials $(\sim 10 \%)$.

\subsection{Determination of the coefficient of friction}

Figure 3 shows the values of the coefficient of friction obtained for each material, which were obtained after the stabilization period of 20.000 test cycles.

The composite N6610\%CF29\%PTFE exhibited a coefficient of friction of 0.16 - the lowest of the values found. This may be explained by the reinforcements present in this composite, PTFE and carbon fiber. Both are considered solid lubricants, that is, the reinforcements help the material to slide, reducing its friction value.

The N6625\%FG15\%AF composite showed a coefficient of friction of 0.16 - a value as low as the PTFE and carbon fiber composites. The N6620AF composite obtained a coefficient of friction of 0.17 - a value similar to PTFEreinforced composites.

The N6630\%FG15\%PTFE composite obtained coefficient of friction of 0.19 . This value was mid-range when considering only the highest and the lowest values found for composites with nylon matrices. This is because the reinforcements are PTFE, which is considered a solid lubricant, and fiberglass, which is considered abrasive. The N6635\%FG composite, which contains only fiberglass reinforcement, showed a coefficient of friction of 0.22 . This 


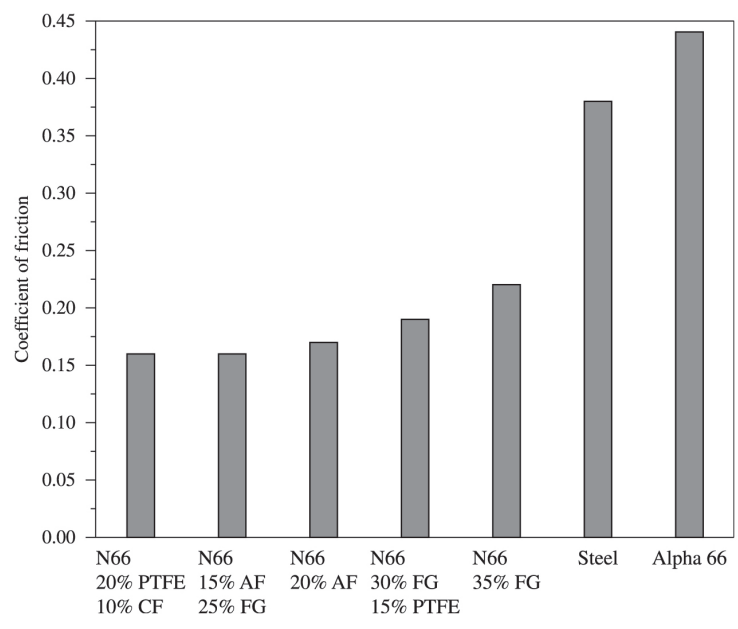

Figure 3. The coefficient of friction for the materials studied.

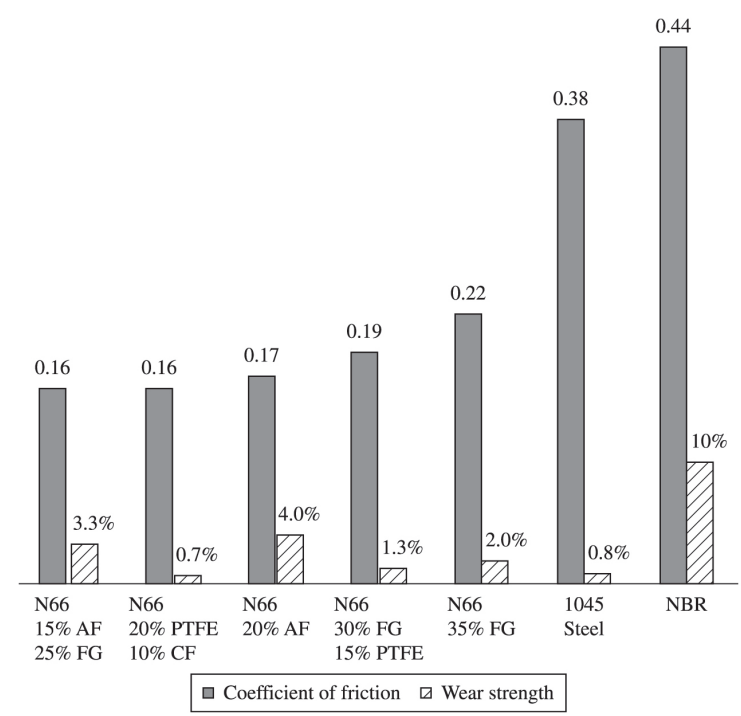

Figure 4. Comparison between the friction coefficient and wear.

value was the highest among the nylon composites, and it can be explained by the fact that fiberglass is considered an abrasive element. In general, N66 matrix composites produced very similar results.

In the case of Alpha 66, the coefficient of friction obtained was 0.44 . Alpha 66 had the highest coefficient of friction, at double that of N66. This is due to differences between the properties of rubber and those of thermoplastic composites.

The SAE 1045 carbon steel exhibited a coefficient of friction of 0.38 . We observed that the coefficient of friction of this material is much higher than that of the nylon composites, being almost equal to that of the rubber. This material has a different properties than the other materials tested, as there is no lubricant in its composition. For most metals, wear occurs because the subsurface layers harden until micro-cracks develop through the coalescence of micro-cavities. Sheets of material are oxidized, broken, and they then break away. The surface roughness increases and the damage is exacerbated by debris ${ }^{22,23,24}$. Wear particles produced during the test oxidize, and these increase the coefficient of friction of the surfaces in contact.

\subsection{Comparison of wear and friction tests}

Figure 4 shows the comparison between the wear resistance and coefficient of friction data resulting from the tests in this study.

The results show that the five types of nylon composite studied obtained low and very similar values for the coefficient of friction. This may be due to the greater amount of material in the N66 composites (matrix), indicating the superior influence of this material on the coefficient of friction. Nylon can also be considered a lubricant, albeit of a lesser intensity than PTFE or carbon fiber. The nylon composite with a PTFE load had lower coefficients of friction and low wear, as PTFE is a solid lubricant and is very resistant to wear (see Figure 4). This factor also corroborates the results found for the carbon fiber composite; a mixture of the two composites resulted in low values for the coefficient of friction and the wear percentage

The coefficient of friction for the composite with $35 \%$ fiberglass was slightly higher for this class of materials, which can be explained by its wear mechanism - breaking, exposure and tearing of high-strength fibers during the wear process ${ }^{25}$. However, the higher coefficient of friction obtained for fiberglass-reinforced composites was not of decisive influence for their wear resistance.

Steel has a mid-range coefficient of friction when compared to N66 composites and Alpha 66. Figure 4 shows that the coefficient of friction of steel was almost twice that of the N66 composites, and its wear was similar to the carbon-fiber-reinforced composite and those with PTFE loads (PA6610\%FC20\%PTFE), the latter having showed the lowest wear percentage of any material under study here.

Alpha 66 has twice the coefficient of friction of reinforced N66 composites due to its strong adhesive property and low wear resistance.

Gustavo Cueva et al. ${ }^{26}$ determined that the coefficient of friction has a direct relationship with the wear of brake discs made of cast iron. We observed that the materials that most wore were those that exhibited the greatest applied forces and highest coefficients of friction in disks during the tests ${ }^{26}$. This direct relationship between the coefficient of friction and wear resistance may be valid for similar tribological pairs that present common types of wear. In fact, as exemplified in K. H. ZumGahr ${ }^{1}$, tribological ceramicceramic and ceramic-metal pairs produce low intensities of wear, but not necessarily low coefficients of friction. On the other hand, a ceramic-polymer pair produces lower friction values, although wear intensity is high ${ }^{1}$. This behavior may be related to the tribological pair under study, since the wear test results show that the properties of each material cause differences in tribological behavior. Therefore, descriptions of the bodies in contact are particularly important.

The results of this experiment demonstrate that the metal-metal pair had a higher coefficient of friction than the metal-composite pair, although wear resistance was equal or even higher, depending on the type of composite being analyzed. For the case of the metal-rubber pair, the coefficient of friction was high and the wear resistance was 
the lowest of the materials tested. The metal-composite pairs produced similar coefficients of friction, which may be related to the N66 matrix. On the other hand, wear resistance varies widely among these materials, which reflects the influence of reinforcement on the wear resistance of these composites.

It can thus be concluded that the coefficient of friction has no direct relationship with wear resistance but rather with the tribological pair being studied. Furthermore, the reinforcement has a great influence on the wear resistance of materials.

Importantly, the material with the highest coefficient of friction will not always have the greatest wear. Other factors to consider are the hardness of the material, the working temperature and if the material is lubricating or not. If the material is not lubricating, it creates adverse outcomes.

The N6610\%CF20\%PTFE composite stands out for its greater wear resistance and lower coefficient of friction. However, if a project involves a high amount of friction, the best sacrificial material is Alpha 66, despite its wear factor.

\section{Conclusions}

We observed that the lubricating reinforcements added to the N66 matrix composites significantly modified the wear strength of the materials studied. The material with the greatest resistance to wear was N6610\%CF20\%PTFE $(0.7 \%)$. Steel, the material with the higher mechanical strength, showed wear resistance $(0.8 \%)$ similar to N6610\%CF20\%PTFE.

Among the composites studied, those containing aramid fiber (N6630\%AF), showed the least wear resistance

\section{References}

1. ZumGahr KH. Microstructure and wear of materials. Amsterdam: Elsevier; 1987. 560 p. Tribology, 10.

2. Davis JR. Surface Engineering for corrosion and wear resistance. Ohio: ASM International; 2001. 279 p.

3. Budinski KG. Surface engineering for wear resistance. New Jersey: Prentice Hall; 1988.

4. Norma DIN 50320: análise sistemática dos processos de desgaste. Classificação dos fenômenos de desgaste. Metalurgia e Materiais. 1997; 53:619-622.

5. Kuhn H and Medlin D. ASM Handbook: mechanical testing and evaluation. ASM International; 2000. v. 8.

6. Lacerda AC, Araújo VHL, Mattos GB, Seixas ML, Moraes GA, Baptista ALB and Ribas PRF. Fatores que afetam a resistência ao desgaste de aços e ferros fundidos utilizados em componentes mecânicos que trabalham em mineração. In: Anais do 57 Congresso Internacional da ABM; 2002; São Paulo. 2002. p. 1810-1819.

7. Unal H, Sen $\mathrm{U}$ and Mimaroglu A. Abrasive wear behaviour of polymeric materials. Materials \& Design. 2005; 26(8):705-710. http://dx.doi.org/10.1016/j.matdes.2004.09.004.

8. Charles DF, Gnanamoorthy R and Ravindran P. Rolling contact fatigue behavior of polyamide clay reinforced nanocomposite effect of load and speed. Wear. 2010; 269(7-8):565-571. http:// dx.doi.org/10.1016/j.wear.2010.06.003.

9. Stachowiak GB, Stachowiak GW and Celliers O. Ballcratering abrasion tests of high-Cr white cast irons. Tribology
(4\%). The composites with fiberglass (N6635\%FG) showed $2 \%$ wear. The composite with fiberglass and aramid fiber (N6625\%FG15\%AF) showed a intermediate wear percentage $(3.3 \%)$. Thus, it is apparent that aramid fibers decrease the wear resistance of the materials. The N6630\%FG15\%PTFE composite exhibited wear of $1.3 \%$. This rate of wear was influenced by the lubrication generated by the PTFE and the strength provided by the fiberglass. Therefore, the type of reinforcement significantly influences the wear resistance of composites. The material with the worst performance in terms of wear resistance was Alpha 66 , with $10 \%$.

The coefficient of friction is directly related to the materials being studied. The nylon matrix determines the coefficient of friction for composites -0.16 for N6610\%CF20\%PTFE and N6625\%FG15\%AF and $0.17 \% \mathrm{~N} 20 \% \mathrm{AF}$. However, this parameter begins to be influenced by fiberglass at higher amounts. The coefficient of friction was 0.19 for N6630\%FG15\%PTFE and $0.22 \%$ for $\mathrm{N} 6635 \% \mathrm{FG}$.

The coefficient of friction was different for the other materials studied, ranging from 0.38 to 0.44 for steel and Alpha 66. It can thus be concluded that the coefficient of friction has no direct relation to wear resistance, but rather to the tribological pair being studied.

\section{Acknowledgments}

The authors gratefully acknowledge Schaeffler Brazil Ltd. for providing the laboratories facilities.

International. 2005; 38(11-12):1076-1087. http://dx.doi. org/10.1016/j.triboint.2005.07.035.

10. Liu CZ, Ren LQ, Tong J, Green SM and Arnell RD. Effects of operating parameters on the lubricated wear behavior of a PA-6/ UHMWPE blend: a statistical analysis. Wear. 2002; 253(78):878-884. http://dx.doi.org/10.1016/S0043-1648(02)001722 .

11. Yu S, Hu H and Yin J. Effect of rubber on tribological behaviors of polyamide 66 under dry and water lubricated sliding. Wear. 2008; 265(3-4):361-366. http://dx.doi.org/10.1016/j. wear.2007.11.006

12. Manual for rubber industry. Leverkusen: Bayer AG, Development Section; 1993.

13. Gregori IRS. Estudo da influência do material de atrito dos discos de embreagem sobre o fenômeno de trepidação (Judder) em veículos. [Dissertation in Mechanical Engineering]. São Bernardo do Campo: Centro Universitário da FEI; 2010.

14. Associação Brasileira de Normas Técnicas-ABNT. NBR 6050: Embreagem. Rio de Janeiro; 1995. 10 p.

15. Duque EL. Desenvolvimento de um modelo de simulação do acoplamento da embreagem durante a partida do veículo. [Dissertation in Mechanical Engineering]. São Bernardo do Campo: Centro Universitário da FEI; 2010.

16. Pantaleón E, Tanaka DK and Bernardes FG. Analise das variações do coeficiente de atrito e as correlações com os mecanismos de desgaste. Holos. 2012; 1(0):62-72. http:// dx.doi.org/10.15628/holos.2012.808. 
17. Laranjeira SM. Estudo do comportamento ao atrito e desgaste de poliamidas. [Dissertation in Mechanical Engineering]. Aveiro: Universidade de Aveiro; 2011.

18. Faullant P. Particle size effects of tin sulfides in disc brake pads. In: Proceedings of the 20 Annual Brake Colloquium and Exposition; 2002; Phoenix. Warrendale: Society of Automotive Engineers; 2002. p. 85-94.

19. Zangiacomi MH and Bittencourt E. Compósitos poliméricos reforçados com fibras de PANox e Fibra de Aramida. Ciência \& Engenharia. 2006; 15(1-2):55-61.

20. Bolvari A, Glenn S, Janssen R and Ellis C. Wear and friction of aramid fiber and polytetrafluoroethylene filled composites. Wear. 1997; 203-204:697-702. http://dx.doi.org/10.1016/ S0043-1648(96)07446-7.

21. Chang KK. Aramid fibers. In: ASM International. ASM International Handbook. 2001. p. 41-45. v. 21.

22. Gaul DJ and Duquette DJ. The effect of fretting and environment on fatigue crack initiation and early propagation in a quenched and tempered 4130 Steel. Metallurgical Transactions. 1980; 11A(9):1555-1561. http://dx.doi.org/10.1007/BF02654519.

23. Rossino LS, Baptista CARP, Shigue CY and Reis FP. Fretting fatigue behavior and contact load evolution in commercially pure titanium. Matéria. 2004; 9:269-304.

24. Baptista CARP, Rossino LS, Torres MAS and Shigue CY. Evaluation of the fretting fatigue behavior of commercially pure titanium. Proceedings of the Institution of Mechanical Engineers. Part L: Journal of Materials Design and Applications. 2007; 221:143-150.

25. Melo LCR, Ferreira M and Costa CA. Desenvolvimento de revestimentos poliméricos para linhas flexíveis submersas. In: Anais do 2 Congresso Brasileiro de P\&D em Petróleo e Gás; 2001; Rio de Janeiro. 2001.

26. Cueva G, Tschiptschin AP, Sinatora A and Guesser W. Desgaste em discos de freios de veículos automotores. In: Cogresso Brasileiro de Engenharia Mecânica. In: Proceedings of 16 COBEM; 2001; Uberlândia. São Paulo: Associação Brasileira de Ciências Mecânicas; 2001. p. 135-142. v. 1. 